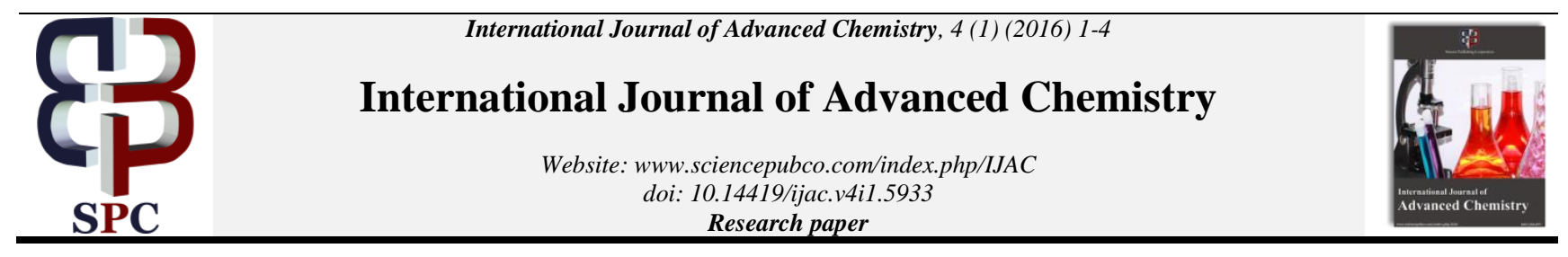

\title{
Ultrasonic study of molecular interactions in binary mixtures of methyl methacrylate(MMA) with toluene and dimethylacetamide at $318 \mathrm{~K}$
}

\author{
R.G. Indhumathi* \\ Department of Physics, Voohrees College, Thiruvalluvar University, Vellore-632 001, TN, INDIA \\ *Corresponding author E-mail:indhu3686@gmail.com
}

\begin{abstract}
The ultrasonic velocity, density and viscosity at $318 \mathrm{~K}$ have been measured in the binary systems of Methyl methacrylate + Toluene and Methyl methacrylate + Dimethylacetamide. In this work an attempt has been made for the first time to investigate the behavior of binary solutions of Methylmethacrylate(MMA) in Toluene and Dimethylacetamide(DMAC) with regard to acoustical parameters such as adiabatic compressibility $(\beta)$, intermolecular free length $\left(\mathrm{l}_{\mathrm{f}}\right)$, free volume $\left(\mathrm{V}_{\mathrm{f}}\right)$, Rao's constant $(\mathrm{R})$, Wada's constant $(\mathrm{W})$ and specific acoustical impedance $(\mathrm{Z})$ from ultrasonic measurements at $318 \mathrm{~K}$ were calculated. The results are interpreted in terms of molecular interaction between the components of mixtures.
\end{abstract}

Keywords: Acoustical Impedance; Acoustical Parameters; Free Volume; Rao's Constant; Ultrasonic Velocity; Wada's Constant.

\section{Introduction}

Ultrasonic technique has been adequately employed to investigate the properties of any substance to understand the nature of molecular interactions in pure liquid, liquid mixtures and ionic interactions in electrolytic solutions. Though the molecular interaction studies can be best carried out through spectroscopic methods, the other non-spectroscopic methods such as dielectric, magnetic, ultrasonic velocity and viscosity measurements have been widely used in the field of interactions and structural aspect evaluations studies. Understanding the nature of molecular systems, physiochemical behavior and molecular interactions in liquid mixtures, the measurement of ultrasonic velocity has been extensively applied.

\section{Experimental method}

Methyl methacrylate solutions in two different organic solvents (Toluene and Dimethyl Acetamide) were prepared in the concentration range $0 \%$ to $100 \%$ in steps of $10 \%$. The samples were added to the solvent taken in bottles with air tight bids. The content of the bottle were shaken periodically and allow dissolving at the required temperature. Enough time was given for MMA to dissolve and clear solutions were obtained. All measurements were made within 2 or 3 days of preparation. The binary mixtures were prepared by using analytical regent grade of Toluene and Dimethylacetamide with different concentration of Methyl methacrylate from $0 \%$ to $100 \%$ in steps of $10 \%$. The density of pure liquids and mixtures are measured using a $10 \mathrm{ml}$ specific gravity bottle. The specific gravity bottle with the experimental liquid is immersed in a temperature controlled water bath. The viscosities of MMA + Toluene and DMAC were determined using an Ubbelohode vis- cometer. The ultrasonic velocity was measured at a frequency of $1 \mathrm{MHZ}$ at temperature $318 \mathrm{~K}$. Its accuracy is $\pm 5 \mathrm{~m} / \mathrm{s}$.

\section{Results and discussion}

Various acoustical parameters such as adiabatic compressibility (M.Aravinthraj et al. 2011, p. 6), acoustical Impedance, intermolecular free length, free volume, Wada's constant and Rao's constant (S.Mullainathan and S.Nithiyanantham 2010, p. 354) were calculated using the experimental data of ultrasonic velocity, density and viscosity.

The measured parameters viz., ultrasonic velocity $(\mathrm{U})$, density $(\rho)$ and viscosity $(\eta)$ are given in table-1. In MMA+Toluene system, the values of viscosity increases linearly with concentration. The density values in this system increases with the increase in concentration of MMA. The velocity decreases with increase in concentration of MMA. In MMA + DMAC system, the values of viscosity decreases linearly with concentration. The density values in this system decreases with the increase in concentration of MMA. The velocity decreases with increase in concentration of MMA. The study of density and viscosity shows there may be structural changes in the molecules of MMA + Toluene [16]. The computed other parameters like adiabatic compressibility, acoustical impedance, free length, free volume, Wada's constant (W) and Rao's Constant(R) are given in table- 2 and table- 3 . Tables -2, 3 show that, in MMA + Toluene system, acoustic impedance decreases with increase in concentration. Adiabatic compressibility increases with increase in concentration of MMA. Free length increases with concentration. Free volume decreases with increase in concentration of MMA, which shows there is solute-solvent interaction in MMA+Toluene system [9-13]. Rao's constant decreases with increase in concentration of MMA. Wada's constant called molecular compressibility decreases with increase in con- 
centration of MMA. In MMA+DMAC system, acoustical impedance decreases with increase in concentration. Adiabatic compressibility increases with increase in concentration of MMA. Free length increases with concentration of MMA. Rao's constant and Wada's constant increases with increase in concentration of
MMA. Free Volume in MMA + DMAC system increases with increase in concentration of MMA, which are also evidenced from figures.

Table 1: Valuesof Density, Viscosity and Ultrasonic Velocity at $318 \mathrm{~K}$

\begin{tabular}{|c|c|c|c|c|c|c|}
\hline \multirow{2}{*}{$\begin{array}{c}\text { Concentration } \\
\text { of MMA } \\
(\text { In Vol. \%) }\end{array}$} & \multicolumn{2}{|c|}{ 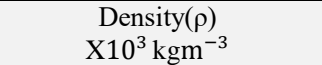 } & \multicolumn{2}{|c|}{ 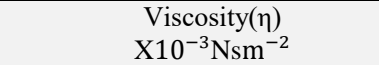 } & \multicolumn{2}{|c|}{$\begin{array}{c}\text { Velocity(U) } \\
\mathrm{ms}^{-1}\end{array}$} \\
\hline & Toluene & DMAC & Toluene & DMAC & Toluene & DMAC \\
\hline 0 & 0.8718 & 0.9547 & 5.1966 & 9.4240 & 1397 & 1384 \\
\hline 10 & 0.8789 & 0.9544 & 5.3018 & 9.0568 & 1218 & 1367 \\
\hline 20 & 0.8844 & 0.9543 & 5.3771 & 8.6008 & 1199 & 1354 \\
\hline 30 & 0.8939 & 0.9542 & 5.4562 & 8.1449 & 1189 & 1318 \\
\hline 40 & 0.9004 & 0.9541 & 5.5388 & 7.9165 & 1182 & 1297 \\
\hline 50 & 0.9063 & 0.9540 & 5.6183 & 7.6428 & 1170 & 1273 \\
\hline 70 & 0.9194 & 0.9509 & 5.7872 & 6.9151 & 1144 & 1206 \\
\hline 80 & 0.9279 & 0.9490 & 5.8850 & 6.6071 & 1140 & 1174 \\
\hline 90 & 0.9375 & 0.9450 & 5.9906 & 6.3539 & 1131 & 1143 \\
\hline 100 & 0.9416 & 0.9416 & 6.0617 & 6.0617 & 1118 & 1118 \\
\hline
\end{tabular}

Table 2: Valuesof Adiabatic Compressibility, Acoustical Impedance and Free Length

\begin{tabular}{|c|c|c|c|c|c|c|}
\hline \multirow{2}{*}{$\begin{array}{l}\text { Concentrationof MMA } \\
\text { (In Vol. \%) }\end{array}$} & \multicolumn{2}{|c|}{$\begin{array}{l}\text { AcousticalImpedance (Z) } \\
\mathrm{X} 10^{6} \mathrm{kgm}^{-2} \mathrm{~s}^{-1}\end{array}$} & \multicolumn{2}{|c|}{$\begin{array}{c}\text { AdiabaticCompressibility }(\beta) \\
\mathrm{X} 10^{-10} \mathrm{Nsm}^{-2}\end{array}$} & \multicolumn{2}{|c|}{$\begin{array}{l}\text { FreeLength }\left(\mathrm{l}_{\mathrm{f}}\right) \\
\quad \times 10^{-11} \mathrm{~m}\end{array}$} \\
\hline & Toluene & DMAC & Toluene & DMAC & Toluene & DMAC \\
\hline 0 & 1.2183 & 1.3212 & 5.8737 & 5.4696 & 4.9339 & 4.7612 \\
\hline 10 & 1.0701 & 1.3048 & 7.6751 & 5.6058 & 5.6400 & 4.8201 \\
\hline 20 & 1.0605 & 1.2924 & 7.8633 & 5.7133 & 5.7087 & 4.8661 \\
\hline 30 & 1.0630 & 1.2579 & 7.9111 & 6.0302 & 5.7260 & 4.9992 \\
\hline 40 & 1.0644 & 1.2377 & 7.9473 & 6.2277 & 5.7391 & 5.0804 \\
\hline 50 & 1.0601 & 1.2147 & 8.0645 & 6.4653 & 5.7813 & 5.1764 \\
\hline 70 & 1.0518 & 1.1471 & 8.3108 & 7.2269 & 5.8689 & 5.4728 \\
\hline 80 & 1.0579 & 1.1141 & 8.2904 & 7.6453 & 5.8617 & 5.6290 \\
\hline 90 & 1.0598 & 1.0801 & 8.3462 & 8.0998 & 5.8814 & 5.7939 \\
\hline 100 & 1.0527 & 1.0527 & 8.4966 & 8.4966 & 5.9341 & 5.9341 \\
\hline
\end{tabular}

Table 3: Valuesof Free Volume, Rao's Constant and Wada's Constant

\begin{tabular}{|c|c|c|c|c|c|c|}
\hline \multirow{2}{*}{$\begin{array}{l}\text { Concentration of MMA } \\
\text { (In Vol. \%) }\end{array}$} & \multicolumn{2}{|c|}{$\begin{array}{l}\text { FreeVolume }\left(\mathrm{V}_{\mathrm{f}}\right) \\
\mathrm{X} 10^{15} \mathrm{~m}^{3} \mathrm{~mol}^{-1}\end{array}$} & \multicolumn{2}{|c|}{$\begin{array}{l}\text { Rao'sConstant(R) } \\
\mathrm{X} 10^{-3} \mathrm{~mol}^{-1} \mathrm{~ms}^{-1}\end{array}$} & \multicolumn{2}{|c|}{$\begin{array}{l}\text { Wada'sConstant(W) } \\
\mathrm{X} 10^{-3} \mathrm{~m}^{3} \mathrm{~mol}^{-1}\end{array}$} \\
\hline & Toluene & DMAC & Toluene & DMAC & Toluene & DMAC \\
\hline 0 & 1.3427 & 0.4981 & 1.1816 & 1.0169 & 2.2037 & 1.9222 \\
\hline 10 & 1.0734 & 0.5203 & 1.1291 & 1.0145 & 2.1220 & 1.9187 \\
\hline 20 & 1.0404 & 0.5751 & 1.1259 & 1.0365 & 2.1196 & 1.9612 \\
\hline 30 & 1.0180 & 0.6115 & 1.1203 & 1.0413 & 2.1131 & 1.9726 \\
\hline 40 & 0.9989 & 0.6357 & 1.1193 & 1.0499 & 2.1139 & 1.9905 \\
\hline 50 & 0.9746 & 0.6653 & 1.1174 & 1.0580 & 2.1134 & 2.0076 \\
\hline 60 & 0.9584 & 0.6544 & 1.1175 & 1.0611 & 2.1160 & 2.0167 \\
\hline 70 & 0.9243 & 0.7436 & 1.1177 & 1.0723 & 2.1089 & 2.0391 \\
\hline 80 & 0.9078 & 0.7813 & 1.1091 & 1.0803 & 2.1073 & 2.0564 \\
\hline 90 & 0.8833 & 0.8134 & 1.1036 & 1.0910 & 2.1007 & 2.0781 \\
\hline 100 & 0.8639 & 0.8639 & 1.1036 & 1.1036 & 2.1031 & 2.1031 \\
\hline
\end{tabular}

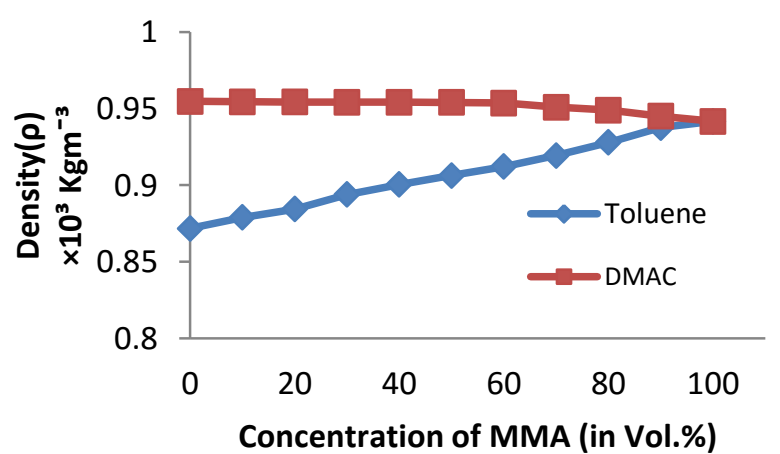

Fig. 1: Concentration Versus Density at 318K.

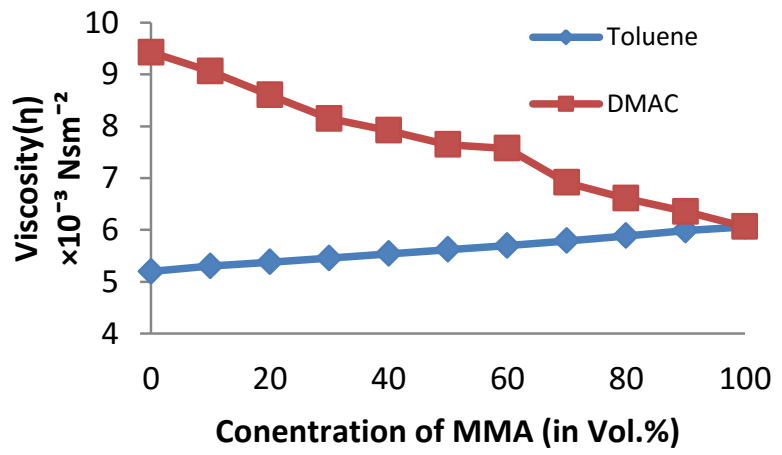

Fig. 2: Concentration Versus Viscosity at $318 \mathrm{~K}$ 


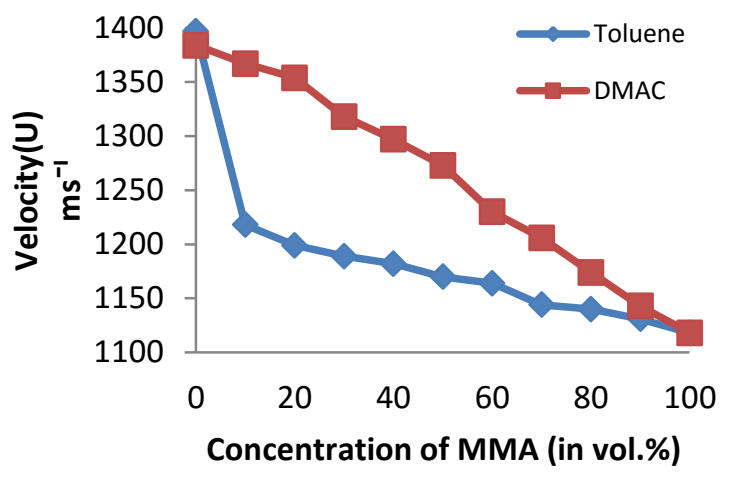

Fig. 3: Concentration Versus Velocity at 318K.

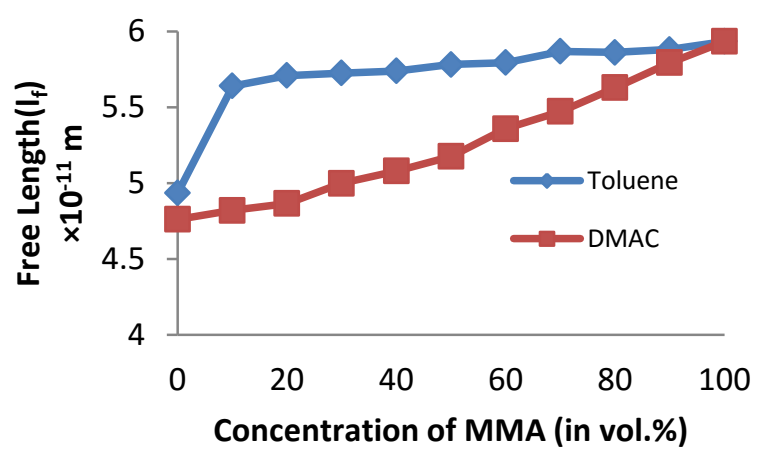

Fig. 5: Concentration Versus Free length at $318 \mathrm{~K}$

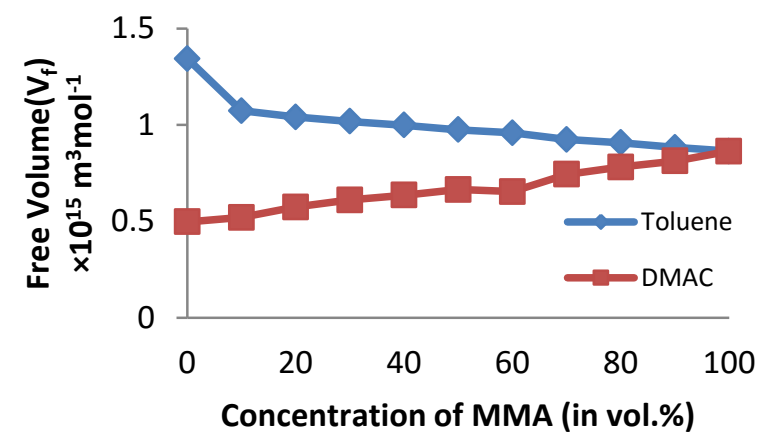

Fig. 7: Concentration Versus Free Volume at $318 \mathrm{~K}$.

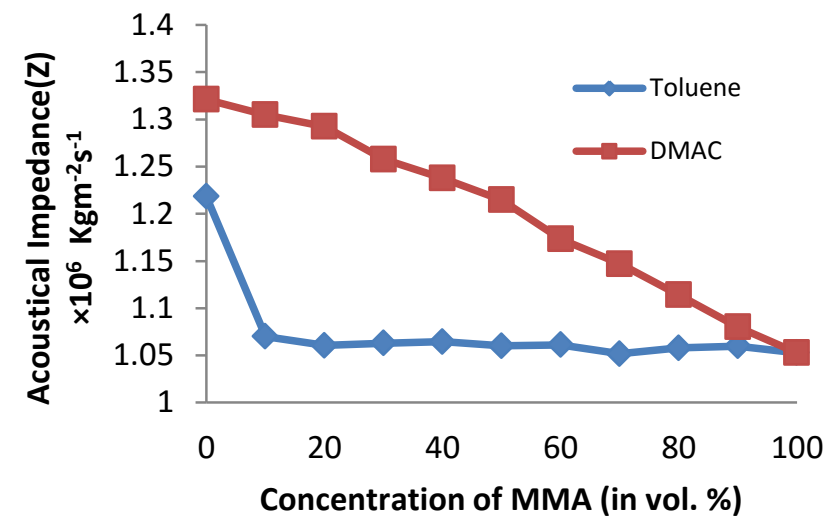

Fig. 4: Concentration Versus Acoustical Impedance at 318K.

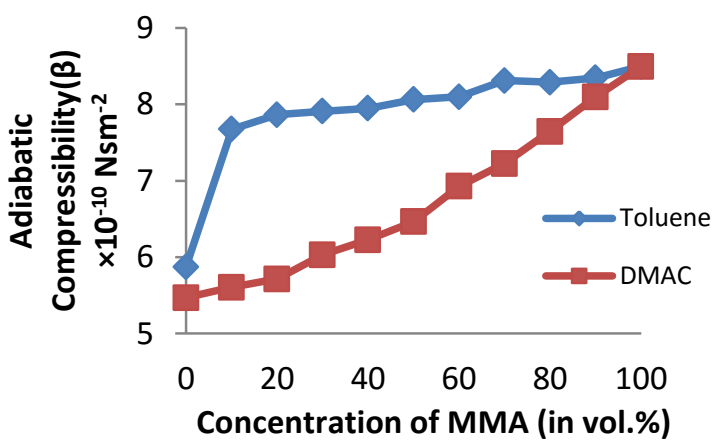

Fig. 6: Concentration Versus Adiabatic compressibility at $318 \mathrm{~K}$

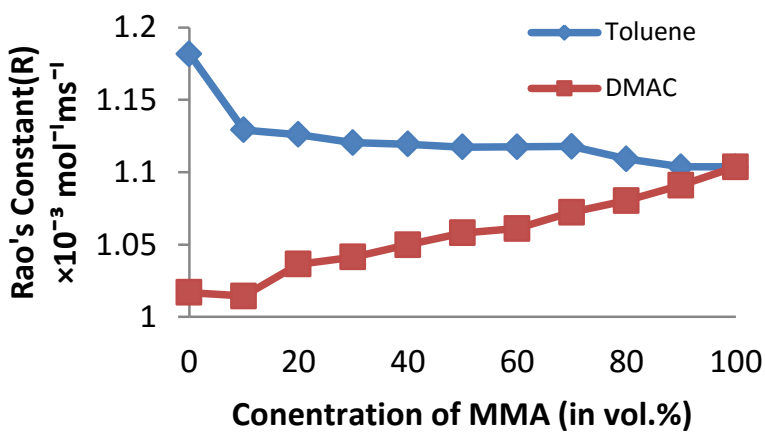

Fig. 8: Concentration Versus Rao's Constant at 318K.

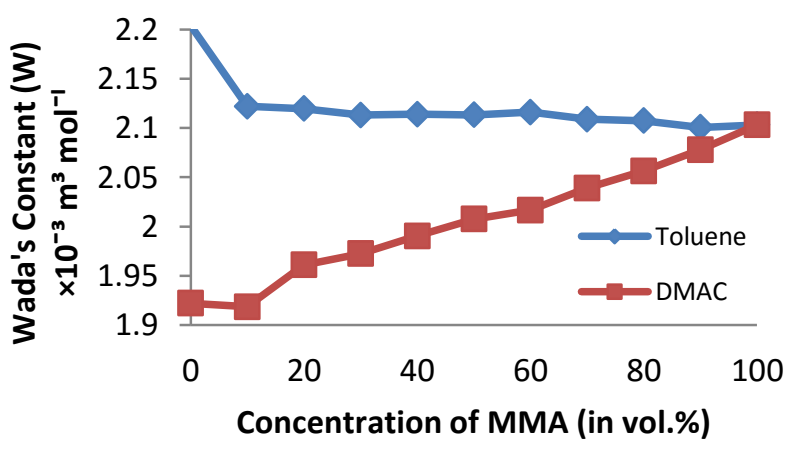

Fig. 9: Concentration Versus Wada's Constant at 318K.

\section{Conclusion}

The ultrasonic velocity, density, viscosity and other related parameters were calculated. The study of density and viscosity shows there may be structural changes in the molecules of MMA + Toluene. A progressive decrease in free volume in MMA + Toluene mixtures clearly indicates the existence of solute-solvent interaction, due to which the structural arrangement is considera- bly affected. The existence of type of molecular interaction in solute-solvent is favored in MMA+Toluene system, confirmed from the free volume, viscosity and acoustical impedance values. Toluene is the better solvent compared to DMAC in MMA, even though both are poor solvents. 


\section{References}

[1] S. Mullainathan and S. Nithiyanantham (2010) "Ultrasonic study of Molecular Interactions in Binary Mixtures at 303 K" E-J. Chem. Vol. 7, No. 2, p. 353-356. http://dx.doi.org/10.1155/2010/264929.

[2] R. Natrajan and P. Ramesh (2011), "Ultrasonic velocity determination in binary liquid mixtures", J. Pure appl. And Ind. Phys, vol. 1, no. 4 , pp. 252-258.

[3] K. Rajagopal and S. Chenthilnath (2010) "Molecular intereaction studies and theoretical estimation of ultrasonic speeds using scaled particle theory in binary mixtures of toluene with homologous nitriles at different temperatures "ThermochimicaActa, Vol. 498, No.1-2, p. 45-53. http://dx.doi.org/10.1016/j.tca.2009.10.001.

[4] Nithiyanantham S. and Palaniappan (2013) "Physiochemical Studies on some Disaccharides in Aqueous Media at 298.15 K" Chem.Sci. Trans. vol.2, No.1, p.35-40. http://dx.doi.org/10.7598/cst2013.262.

[5] A.N.Sonar and N.S. Pawar (2010) "Ultrasonic Velocity, Density And Viscosity Measurement Of Substituted Heterocyclic Drugs In 1, 4-Dioxane At 303 K" Rasayan j. Chem. Vol. 3, No. 1, p. 38-43.

[6] N.Santhi, P.L.Sabarathinam, M.Emayavaramban, C.Gopi and C.Manivannan (2010) "Molecular Interaction Studies in Binary Liquid Mixtures from Ultrasonic Data" E-Journal of chemistry, Vol. 7, No. 2, p. 648-654.

[7] S. Thirumaran and K. Job Sabu (2009) "Ultrasonic investigation of amino acids in aqueous sodium acetate medium" Ind. J. Pure \& App. Phy., Vol. 47, p. 87-96.

[8] A. K. Gupta, K. Kumar and B. K. Karn, "Studies of binary liquid mixtures of o-cresol with ethylmethyl ketone, acetone acetophenone and ethylacetate", J. Ind. Coun. Chem., vol. 26, No.1, (2009)p. 77-81.

[9] P.Vasantharani,V.Pandian and A.N.Kannappan (2009) "Ultrasonic velocity,viscosity, Density and Excess Properties of Ternary Mixture of N-Methyl cyclohexylamine+Benzene+1-Propanol" Asian J. Appl. Sci., Malaysia, Vol.2, No.2, p. 169-176.

[10] S.Parveen, S.Singh, D.Shukla, K.P.Singh, M.Gupta and J.P.Shukla, (2009) "Molecular Interaction study of binary mixtures of THF with methanol and o-cresol-an optical and ultrasonic study", ACTA PhysicaPolonica A, Vol. 116, No.6, p. 1011-1017.

[11] M.Aravinthraj, S.Venkatesan and M.Kamaraj (2011) "Molecular interaction studies between H-bonded ternary mixtures of p-cresol with simple aldehydes in cyclohexane at different temperatures", ijcepr, Vol. 2, No. 1, p. 5-11.

[12] Eyring, H. and Kincaid J.F, 1938. Free volumes and free angle ratio of molecules in liquids.J. Chem. Phys., vol. 6, (1938) p. 620-629. http://dx.doi.org/10.1063/1.1750134.

[13] Chandra Mohan Saxena and SaxenaArchna and Shukla Naveen Kumar (2013) "Ultrasonic studies and molecular interactions of binary liquid mixture of ethylamine and benzyle alcohol at 313.15 K", Res. J. chem. Sci., Vol. 3, No. 5, p. 10-13.

[14] Jacobson B, Acta Chem Scand. 1952, vol. 6, p. 1485.http://dx.doi.org/10.3891/acta.chem.scand.06-1485.

[15] M. K. Rawat , Sangeeta(2008) "Ultrasonic study of molecular interactions and compressibility behavior of strontium soaps in chloroform-propylene glycol mixture" Ind. J. Pure Appl. Phy., Vol. 46, p. 187-192.

[16] R. Nithya, S. Nithyanantham, S. Mullainathan and M. Rajasekaran (2009) "Ultrasonic investigation of molecular interactions in binary mixtures at 303 K", E-J. Chem., Vol. 6, No.1, p. 138-140.

[17] Vogel's, G.H. Jaeffery, S. Bassetl, R.C. Denney (1997) Text book of quantitative chemical analysis, $\mathrm{V}^{\text {th }}$ edition, ELBS Longman, 53.

[18] S.Parveen, D.Shukla, S.Singh, K.P.Singh, M.Gupta, J.P.Shukla, Appl. Acoust. 2009, Vol.70, p. 507 http://dx.doi.org/10.1016/j.apacoust.2008.05.008.

[19] G. R. Bedare, V. D. Bhandakkar\& B. M. Suryavanshi (2013), "Study of molecular interactions in the binary liquid mixtures from acousticc\& thermodynamic parameters at 303 K" IOSR J. Appl Phys, Vol.3, No.3, p. 36-39. 